\title{
MEMÓRIA, EXPERIÊNCIA E NARRATIVA
}

\author{
Myriam Moraes Lins de Barros ${ }^{1}$
}

\begin{abstract}
Do ponto de vista do homem, que vive sempre no intervalo entre o passado e o futuro, o tempo não é um contínuo, um fluxo de ininterrupta sucessão; é partido ao meio, no ponto em que "ele" está; e a posição "dele" não é o presente, na sua acepção usual, mas, antes, uma lacuna no tempo, cuja existência é conservada graças à "sua" luta constante, à sua tomada de posição contra o passado e o futuro.
\end{abstract}

Hannah Arendt

O storyteller, como o flâneur, se distancia do passante massificado através da capacidade de narrar que ele mantém viva. A memória recuperada pelo storyteller não está relacionada à transmissão de uma tradição, mas à comunicação entre as gerações.

Odílio Alves Aguiar

Este artigo sobre memória tem também sua história. Inicialmente publicado nos Anais do Colóquio Individualismo, Sociabilidade e Memória (2009), tenho a satisfação de republicá-lo na revista Iluminuras a convite de Cornelia Eckert e Ana Luiza Carvalho da Rocha. Retomo, assim, o percurso acadêmico que este texto procura traçar.

Começo este texto com uma revisão do título. Quando fui convidada para participar do Colóquio Individualismo, Sociabilidade e Memória, aceitei apresentar minha trajetória de pesquisa sobre memória. Propus um título: Memória e Experiência. Algumas semanas depois, iniciando o texto desta conferência, acrescentei mais uma palavra a estas duas: a narrativa. Este ajuste é uma precisão conceitual e uma definição mais clara dos processos de pesquisa antropológicos sobre memória, nos quais o próprio momento da narrativa é, ele mesmo, momento de construção da memória. A leitura do trabalho de Beatriz Sarlo (2007) que acabara de fazer nesta mesma ocasião foi que me alertou para este esquecimento inicial. Diz a autora ao se reportar à obra de Walter Benjamin: "O que chamamos experiência é o que pode ser posto em relato" (Sarlo, 2007: 26). Assim o título passa a incorporar o termo 'narrativa' e mudando então para Memória, experiência e narrativa.

Realizo, eu mesma, um relato de uma trajetória acadêmica e a inicio com a

\footnotetext{
${ }^{1}$ Universidade Federal do Rio de Janeiro, Brasil.
} 
lembrança de uma experiência recente. Há, exatamente, seis anos atrás escrevi o memorial para o concurso de titular na Escola de Serviço Social da Universidade Federal do Rio de Janeiro ${ }^{2}$. O texto começava com alguns dos muitos aspectos dos estudos de memória: sua seletividade, sua perspectiva social e individual, seu caráter narrativo. Reproduzo aqui o parágrafo inicial:

\begin{abstract}
Há muito tempo tenho trabalhado sobre memória e a ideia básica da memória como uma construção social ganha toda sua expressão no momento em que é preciso debruçar-se sobre si mesmo e iniciar o trabalho de elaboração de uma linha narrativa que apresente uma história de vida acadêmica. Há nesta elaboração uma seleção do que deve ou não estar inserido na história e, neste caso em particular do memorial acadêmico, a seleção está na forma de narrar, nas prioridades que definem as áreas de atuação e na intromissão de elementos externos à trajetória acadêmica.
\end{abstract}

Retomo o texto escrito naquele momento e o reescrevo, sabendo que a cada narração de uma experiência, uma nova versão da trajetória é elaborada em função do momento, dos interlocutores, da continuidade da própria vida. Volto mais uma vez a Beatriz Sarlo:

\footnotetext{
A narração inscreve a experiência numa temporalidade que não é a de seu acontecer (ameaçado desde seu próprio começo pela passagem do tempo e pelo irrepetível), mas a de sua lembrança. A narração também funda uma temporalidade, que a cada repetição e a cada variante torna a se atualizar. (Sarlo, 2007: 24-25)
}

Minha trajetória. Velhice, família, cidade, gerações são os grandes temas das pesquisas que venho desenvolvendo há mais ou menos 30 anos. Estes eixos cruzam-se entre si e com o campo de estudos da memória. Logo no início desta trajetória, em meados da década de 70 , durante o mestrado, a questão da memória não se vislumbrou como uma possibilidade analítica. Naquela ocasião outras questões estavam em cena nas discussões da antropologia urbana.

A partir da orientação de Gilberto Velho, aproximei-me do interacionismo simbólico e das discussões sobre desvio e estigma com Erving Goffman e Howard Becker, assim como da análise histórica de Michel Foucault sobre sexualidade e loucura que tinha áreas de interseção com o campo teórico e de pesquisa sobre desvio social, trazendo, para o centro das discussões, a questão do poder já pautada por Becker e por

\footnotetext{
${ }^{2}$ O Memorial é datado de 01 de setembro de 2005.
} 
Gilberto Velho em seus trabalhos. No caso de Gilberto Velho, há aproximações claras com a tradição antropológica dos estudos de Mary Douglas e de Evans-Pritchard sobre acusação. Assim, a antropologia urbana que se desenvolvia no Museu Nacional na década de 70, o debate sobre identidade social e a discussão sobre desvio social e estigma estiveram no centro das questões sobre as relações sociais nas grandes cidades. Ao mesmo tempo, havia uma sensibilidade para novas formas de organização social e de expressões das identidades sociais numa sociedade em processo de franca transformação em suas mais diferentes esferas. Neste sentido as contribuições teóricas de Raymond Firth, Alfred Shultz, Louis Dumont, Simmel e mais proximamente Gilberto Velho eram e continuam a ser fundamentais para a construção das referências teóricas nos debates em torno do individualismo e da ideologia individualista da sociedade moderno-contemporânea.

A preocupação inicial do meu projeto de dissertação era trabalhar a identidade social de mulheres velhas. O universo entrevistado era composto de mulheres católicas de camadas médias do Rio de Janeiro. Uma das questões teóricas nos estudos sobre as camadas médias que estava presente no conjunto de pesquisas no Museu Nacional era a delimitação sócio-cultural deste universo social em termos de situação e posição de classe e de ethos e visão de mundo. Estas referências teóricas estão presentes em Max Weber, basicamente, nas discussões sobre grupo de status, nas análises de classe de Pierre Bourdieu, interpretações da análise cultural de Geertz, sem contar a discussão inicial do Gilberto Velho quando inicia este campo de trabalho da antropologia urbana com a pesquisa sobre os white collors em Copacabana. Estilos de vida, mundos sociais, ethos, complexidade, heterogeneidade são algumas categorias teóricas que passam a fazer parte de um campo de estudos sobre as camadas médias urbanas, quando se coloca em questão a importância relativa das classes sociais nas construções do ethos e das visões de mundo. Às referências teóricas antropológicas neste campo de estudos sobre camadas médias, soma-se a literatura sociológica de Alfred Shultz e Georg Simmel.

Voltando à pesquisa de dissertação. As mulheres entrevistadas para a pesquisa compunham uma rede social que se criara em torno da figura carismática de D. Helder Câmara. O trabalho assistencial e outras atividades ligadas à CNBB realizados paralelamente à vida profissional e, sobretudo após a aposentadoria, deram o tom para a experiência de velhice ativa das mulheres pesquisadas. Interpretei esta experiência como parte de um projeto que se constituía na velhice como o último projeto de vida. 
Com o título Testemunho de vida: um estudo antropológico de mulheres na velhice, a dissertação foi publicada, em parte, em 1981 na Coleção Perspectivas Antropológicas da Mulher pela Zahar e tendo como organizadoras Maria Luiza Heilborn, Maria Laura Cavalcanti e Bruna Franchetto. A coleção apresentava a questão da mulher como um tema eleito para o debate das ciências sociais em diálogo com o movimento feminista. A proposta teórica e política da coleção era expressa no questionamento da naturalização do lugar da mulher na sociedade, no entendimento do caráter histórico e cultural das identidades femininas e nas múltiplas determinações presentes na construção social destas identidades e estava em ressonância com as discussões do feminismo na academia brasileira daquela época como mostra o estudo realizado por Maria Luiza Heilborn e Bila Sorj sobre a trajetória dos estudos de gênero no Brasil (1999). Portanto, neste momento, o trabalho sobre velhice de mulheres de camadas médias acaba sendo incorporado na publicação no campo dos estudos de gênero. E sem dúvida, inicia- se aí uma área de interseção entre pesquisas sobre velhice e gênero.

Neste contexto acadêmico não se enunciava claramente a relação óbvia entre projeto e memória como pouco depois é elaborado. Se tomarmos a própria noção de projeto (Velho,1981), vemos que a questão da narrativa da trajetória do indivíduo já é, desde o início, definidora do próprio projeto, embora não seja formulado exatamente nestes termos originalmente é, para a existência do próprio projeto há a necessidade de sua comunicação e na sua formulação, desenvolve-se uma narrativa de coerência em uma trajetória de vida fragmentada, portanto de uma vida já vivida e reorganizada neste momento para dar sentido ao projeto e mesmo, em algum grau, apontar para sua possibilidade de efetivação.

A memória vai se constituir, de fato, um interesse teórico a partir da minha pesquisa no doutorado realizado entre 1981 e 1986. A questão que se colocava naquele momento era a das implicações das mudanças sociais e culturais na família, nas relações de gênero na sociedade brasileira, basicamente nos segmentos de camadas médias urbanas.

Os avós foram os personagens centrais desta discussão. A perspectiva dos avós sobre a família permitiu a análise das mudanças sociais e permanências de valores na família e da própria família como um valor social nestas camadas sociais. Ao mesmo tempo a importância dos avós na organização familiar é pensada em função do próprio 
panorama das mudanças na sociedade e, em particular, na família, sobretudo, no que se refere ao lugar da mulher no mundo público e privado. Neste trabalho procuro dialogar com os autores clássicos da literatura brasileira sobre família como Antonio Candido e Gilberto Freyre, com pesquisadores de família contemporâneos, antropólogos, historiadores e psicanalistas, com a tradição de estudos antropológicos sobre parentesco e família. Durante o próprio trabalho de campo tornou-se fundamental a iniciação nas análises sociais da memória individual e social. Foram os próprios avós que ao recorrerem a seu passado na família de origem, acabaram me apontando o percurso teórico da memória como uma instância social e coletiva capaz de ser compreendida pela perspectiva das ciências sociais.

Alguns pontos e algumas conclusões da tese vêm sendo retomados em diferentes pesquisas minhas e de outros pesquisadores. A questão da memória é um dos aspectos que trabalhei neste momento e que retomo nos estudos sobre cidade e velhice. Outro aspecto trabalhado foi o das relações entre as mulheres na família, sobretudo mães e filhas, no momento em que se questionava o lugar da mulher na família e se realizava a concretização das trajetórias profissionais femininas. A experiência na sociedade moderna de uma organização familiar nos moldes de uma família extensa parece ser, também, uma contribuição para os estudos sobre família moderna na sociedade brasileira e sobre as experiências de relações intergeracionais na família que, hoje, alguns antropólogos e sociólogos denominam de solidariedade intergeracional.

Em 1989 havia publicado o artigo "Memória de velhos e família" na Revista Estudos Históricos. Retomava as questões da tese de doutorado sobre memória, aprofundando as leituras dos trabalhos de Maurice Halbwachs. Como parte deste projeto de estudo sobre memória, iniciei mais francamente a interlocução com historiadores e com as temáticas referentes à memória coletiva e a história de grupos sociais.

Em 1992 publiquei com Ilana Strozenberg o livro Álbum de Família editado pela Comunicação Contemporânea. O livro é um ensaio sobre fotografias de família e apresenta os resultados de pesquisa realizada no final da década de $80 \mathrm{com}$ o universo que denominamos os guardiães da memória familiar e com o acervo fotográfico destes indivíduos das camadas médias e altas. No ensaio procuramos mostrar como a fotografia é apreendida pelos narradores como uma captura do real, diferentemente da pintura, e não como uma construção deste real. Em uma linguagem que indica que as 
fotos representam o real e a verdade das relações familiares, os guardiães dos acervos de fotos de família constroem a imagem da família e de sua história referida nas imagens retratadas. O álbum é, assim, interpretado como uma narrativa de memória e cada uma das fotos uma pista das lembranças e em si mesma uma versão possível da memória familiar.

O aprofundamento das questões teóricas estava ainda dentro das discussões sobre família: são as relações familiares, os legados das lembranças na constituição e na importância de acervos fotográficos, a preservação da família como um valor. Memória e família e ou memória da família é também a temática de uma incursão na literatura brasileira com uma análise da obra memorialista de Carlos Drummond de Andrade. Esta experiência prazerosa de associar literatura brasileira e antropologia ainda está em meus projetos para atividades futuras.

A memória da cidade surge a partir das pesquisas "Memória e uso do espaço urbano por velhos na cidade do Rio de Janeiro" e "A construção do espaço urbano ontem e hoje". Este último título, sintético demais, fala das formas e condições em que se vive na cidade do Rio de Janeiro e trata dos significados dados à experiência de vida. A ideia de construção remete, assim, aos significados dados pelos indivíduos com mais de 60 anos à vida urbana, em diferentes contextos sociais.

Nos dois projetos a discussão teórica procurou abranger a literatura sobre a cidade moderna, sobre memória e sobre velhice. Complexidade urbana, heterogeneidade, mundos sociais, fronteiras simbólicas e os valores da modernidade compreendem um conjunto de noções desenvolvidas na antropologia brasileira por Gilberto Velho e que remetem à Simmel e à tradição da Escola de Chicago, como já foi apontado atrás. Nos projetos, a cidade aparece ao mesmo tempo como espaço social constitutivo e construído pelas relações sociais no mundo moderno e como tema para as entrevistas de história de vida. As pesquisas estavam lidando com memórias e lembranças de indivíduos moradores do Rio de Janeiro e buscavam entender os significados atribuídos às transformações urbanas e aos diferentes momentos das trajetórias de vida. No tratamento das questões relativas à cidade, a pesquisa permitiu uma viagem pelas perspectivas históricas na análise da vida urbana, uma releitura da literatura brasileira que tem o Rio de Janeiro como palco dos dramas, das crônicas e dos personagens e, ao mesmo tempo, fazia uma busca de imagens da cidade que era lembrada pelas pessoas que entrevistava. Nestas caminhadas por outros campos levava 
comigo as bolsistas de Iniciação Científica que tiveram que ler Lima Barreto, descobrir o mapa da cidade, as histórias oficiais registradas nas Regiões Administrativas. A viagem literária e histórica fez a aproximação com autores brasileiros que tinham trabalhado a constituição das metrópoles brasileiras na modernidade como Olgária Mattos, Maria Stella Bresciani e Nicolau Svecenko, entre outros. Procurava uma aproximação entre a antropologia compreensiva da história da vida cotidiana e a história da cultura. Neste percurso e inspirada por esta literatura, integro às minhas leituras os trabalhos de Walter Benjamin sobre a cidade moderna, sobre seu personagem típico, o flâneur e sobre a perda do sentido da experiência na sociedade capitalista, apresentada por Benjamin na figura do narrador, impossibilitado de ter a quem transmitir suas experiências. A apreensão desta literatura não se dá pela interpretação benjaminiana da impossibilidade da narrativa, mas pelo que esta interpretação indica: a compreensão das lembranças dos indivíduos como uma construção de tempo-espaço de memória, experiência e narrativa.

Neste momento do percurso das pesquisas, a tentação em trazer para o debate sobre a cidade moderna duas perspectivas distintas se concretiza no diálogo que realizo com Simmel e Benjamin e entre os dois. Na obra dos dois pensadores, a cidade moderna é abordada através de suas relações sociais fundamentadas na ideologia individualista e na economia de mercado onde tudo e todos são transformados em mercadoria e, neste contexto, o homem blasé de Simmel e o flâneur de Benjamin são apresentados como constitutivos das metrópoles modernas. O diálogo entre os autores já estava dado de antemão: a inspiração simmeliana está presente na figura do flâneur e parece uma das influências de Simmel na obra de Benjamin, além do caráter ensaístico das obras dos dois autores. Influência que não se limita a Benjamin, mas que abarca um conjunto de sociólogos e filósofos alemães e sociólogos americanos da Escola de Chicago.

Enquanto as pesquisas eram desenvolvidas, a docência na graduação permitiume realizar um laboratório com os alunos sobre memória da cidade, sobre heterogeneidade urbana, sobre as histórias das transformações urbanísticas e sociais. Os trabalhos dos estudantes trouxeram um amplo panorama de bairros, de modos de vida e de histórias relatadas por entrevistados ou arquivadas nas sedes das regiões administrativas. A amplitude do cenário do Rio de Janeiro e do Grande Rio era possível 
pela própria característica dos alunos de graduação, moradores eles mesmos de diferentes bairros e regiões da cidade ${ }^{3}$.

Nas pesquisas sobre memória dos velhos na cidade, são retomados os pontos fundamentais da análise sociológica de Maurice Halbwachs. Como já disse, em 1989 quando publiquei em Estudos Históricos uma interpretação das fotografias de família, desenvolvi uma breve análise dos trabalhos de Halbwachs. Apontando a herança durkheimiana na conceituação de memória individual, coletiva, social e oficial, mostrava, também, um certo distanciamento do autor frente à posição de Durkheim quando coloca uma margem de opções e de possibilidades de construção das lembranças. Para Halbwachs, embora o homem só possa ter memória de seu passado enquanto ser social, a memória individual é um ponto de vista da memória coletiva e este ponto de vista varia de acordo com o sentimento de realidade, dado pelo lugar que o indivíduo ocupa nas relações sociais. São os quadros sociais de memória do grupo social que darão as referências aos indivíduos. A memória individual é dependente, assim, do lugar de onde se narra as lembranças. O caráter relativo da memória também vai ser congruente com a ideia da memória como uma reconstrução do passado. Outro aspecto fundamental da memória individual e coletiva, e, ainda dentro desta mesma configuração teórica, é o centramento na vida em sociedade, na memória vivida, construída nas experiências de indivíduos inseridos em grupos sociais.

A partir desta apreensão da obra de Halbwachs, utilizo a idéia de Michel Pollak, em artigo publicado no mesmo número de Estudos Históricos (1989), do espaço de conflitos entre diferentes versões das memórias e da história dos grupos sociais e do uso social das lembranças na elaboração da identidade e das fronteiras de grupos e segmentos sociais. Procurando entender as narrativas de memória dentro deste quadro teórico em que a memória é construída e compreendendo que esta construção se dá em um campo sócio-cultural específico, estou mais preocupada em entender versões, as relações entre estas diferentes versões e os lugares sociais a partir dos quais são compostas estas versões. Gênero, geração, situação social são alguns dos aspectos a serem levados em conta nos estudos destas diferenças. A proeminência de um dos aspectos em relação aos outros deve, também, ser avaliada nas análises destas versões. E mais, o próprio momento da narrativa tem que ser considerado para que se

\footnotetext{
${ }^{3}$ Parte desta experiência está relatada em Lins de Barros, 2003.
} 
compreenda a narrativa como uma possibilidade entre outras da construção das lembranças. Não estou lidando, assim, com a perda da figura do narrador ou de lugares da memória na modernidade como é trabalhada por Benjamin ou por Pierre Nora mas com a complexidade e a heterogeneidade na vida moderna e as condições contemporâneas da construção de narrativas baseadas em experiências que trazem a dimensão dinâmica e processual onde se entrelaçam relações de gênero, trajetórias profissionais, locais de moradia, etc.

No trabalho das interpretações das narrativas de lembranças, a perspectiva antropológica é aprofundada nas discussões metodológicas do uso de história de vida e da análise dos depoimentos de lembranças como momentos rituais como trabalha Barbara Myerhoff (1984).

As preocupações teóricas sobre memória estão, assim, assimiladas ao campo teórico da discussão da relação indivíduo/sociedade nas sociedades complexas contemporâneas em uma mesma linhagem teórica dos estudos de Gilberto Velho. Nesta perspectiva teórica as questões dirigem-se para as representações do indivíduo moderno, para a construção da realidade social como processo. Estão compreendidas, neste campo teórico igualmente, as reflexões sobre trajetórias individuais e campos de possibilidades sócio-culturais onde se inserem, portanto, as questões da memória e do projeto de vida.

A definição deste campo teórico iniciado há anos atrás e reavaliado e aprofundado nos processos de pesquisa sobre memória e uso da cidade pelos velhos configurou-se, na verdade, como um plano de estudos para um prazo mais longo. Nos projetos posteriores, a proposta de pesquisa foi no sentido trazer novos questionamentos, mas ainda dentro deste campo de interesses teóricos e metodológicos.

Neste sentido desenvolvo no artigo "O passado no presente: aos 70 falando do Rio de Janeiro" a ideia da construção da identidade de uma geração a partir das narrativas de memória e a percepção dos marcos da cidade como pistas para as lembranças. Apresento, também, neste texto a discussão do direito à cidade por parte desta geração que não consegue mais se identificar com a paisagem urbana e com formas de interações sociais. Ainda com o material das pesquisas sobre memória, cidade e velhice tratei das relações entre densidade dos relatos de memória, gênero e curso da vida. A percepção de que a narrativa tem densidades diferenciadas em função do momento em que se relata a trajetória, das desigualdades de gênero e de classe foi trabalhada na análise das narrativas de homens e mulheres de diferentes segmentos 
sociais, examinando particularmente as memórias de mulheres das classes trabalhadoras de suas trajetórias de vida em relação à família e ao trabalho. Algumas ideias presentes no trabalho "Densidade da memória..." onde estes aspectos da densidade diferenciada são estudados são retomadas e procuro trabalhar o lugar da mulher mais velha na família e nos espaços públicos, sua mobilidade ou não nos percursos urbanos e no lidar com as instituições e, também, sua autonomia frente à família nas escolhas de atividades cotidianas.

Seguindo na mesma linha de pesquisa, procuro em outro momento, trabalhar alguns pontos de uma antropologia das emoções baseada em histórias de vida e uma antropologia/sociologia dos sentidos. No artigo "A cidade dos velhos" (1999), faço um esboço de um caminho de análise entre o sentido da visão identificado por alguns autores como o sentido humano que mais se associa aos valores da modernidade e à experiência nas metrópoles, interpretando o traçado de mapas urbanos feitos pelos velhos nas formas de narrar os espaços da cidade do Rio. Mais uma vez recorro a Simmel e a Benjamin. O primeiro desenvolve uma sociologia dos sentidos e atribui à visão a experiência singular que associo em Benjamin à relação entre o olhar e o ser olhado do flâneur nas metrópoles. E sem dúvida, assim como ocorre com a visão das fotografias pelo narrador a paisagem urbana e seus marcos são, como já tratei atrás, uma chave de partida para uma narrativa.

Construímos nos contextos acadêmicos questões e respostas e retomamos algumas, fazendo uma releitura de trabalhos já realizados (mais uma vez uma narrativa de memória). Em 1998 publico, pela Editora FGV, a coletânea Velhice ou Terceira Idade? Estudos antropológicos sobre identidade, memória e política. Nas reuniões da ABA de 1994 e 1996 a temática da velhice foi debatida por pesquisadores de diferentes centros de pesquisa e mostrou que novos e jovens pesquisadores estavam se somando à primeira geração de antropólogos que se dedicam ao tema da velhice no Brasil. A coletânea reúne trabalhos de autores que haviam apresentado suas pesquisas na Reunião da ABA de 1996 e que representavam, nas ciências sociais, aqueles que estavam produzindo mais efetivamente sobre velhice e envelhecimento. O livro significou para mim a possibilidade de tornar pública uma produção antropológica, portanto, uma perspectiva das ciências sociais sobre temas que poderiam se tornar cativos da área médica ou da gerontologia. Diferentemente destas duas, minha preocupação não era e não é constituir uma área de antropologia da velhice, embora os autores tenham um 
acervo de conhecimento sobre o tema, mas trabalhar a temática a partir dos referenciais teóricos e metodológicos da antropologia e dentro desta tradição. É a partir desta perspectiva que entendo que deva ser estimulada a interlocução com as diferentes áreas de conhecimento e com diferentes instâncias da vida social. Como já foi apresentado atrás, o livro trouxe para um conjunto de pesquisadores a oportunidade de concretizar a rede de pesquisa em torno destas temáticas e desencadear outras publicações na área. Nesta publicação, o artigo derivado da dissertação de mestrado publicado anteriormente em uma coleção de estudos de gênero está agora inserido na parte dedicada à memória, juntamente com os trabalhos de Cornelia Eckert, de Alda B. da Motta e Maria Letícia M. Ferreira. Neste momento já está clara a interseção entre estas diferentes temas de pesquisa: memória, gênero, classe e velhice e, está construída claramente uma rede de pesquisadores.

Ao longo dos trabalhos sobre velhice e cidade, trabalhei com diferentes segmentos sociais e tratei de examinar a construção da memória a partir de distintas perspectivas e perceber a própria constituição de situações propícias a um desencadeamento de lembranças como os espaços de sociabilidade informais e formais. Quando tratamos das lembranças na e da cidade há uma tentação que deve ser sempre observada: a de sobrepor às dimensões de classe e gênero a referência geracional. Tentação movida por um movimento que aparece em algumas ocasiões na mídia e nos espaços de sociabilidade de forma a marcar nostalgicamente as perdas dos lugares de memória sob o ponto de vista geracional e, às vezes, os ganhos permitidos pela modernização da sociedade. Esta via de interpretação das perdas e da construção de uma história sobre o espaço urbano, empregada, muitas vezes, pela própria história oficial, é, ela mesma, um objeto de pesquisa, uma vez que é uma versão entre outras da história das cidades através de seus personagens eleitos pela dimensão geracional.

A guinada para os estudos da juventude logo depois significou uma mudança de perspectiva geracional. Trata-se de pesquisa sobre trajetória de vida em outra situação geracional, ao estudar projetos de vida de jovens universitários de segmentos diferenciados das camadas médias e mesmo das camadas trabalhadoras. Esta incursão trouxe mais claramente a importância de trabalhar trajetórias de vida de diferentes gerações nas perspectivas de gênero e classe. A partir da questão das gerações, volto, assim, recentemente aos estudos de família. A pesquisa tem como foco as mulheres de camadas médias urbanas que estão, aproximadamente, na faixa de idade entre 50 e 60 
anos e que vivem uma experiência bastante comum, atualmente, que é ter pais vivos e filhos jovens e jovens adultos que, muitas vezes, adiaram sua saída da casa dos pais. Um dos objetivos do projeto é expandir e refinar para estes segmentos as discussões sobre redes sociais, solidariedade familiar, autonomia e independência na família nas diferentes gerações, a responsabilidade e sentido de obrigatoriedade em relação aos mais velhos e aos mais jovens. O trabalho de doutorado realizado na década de 80 é, sem dúvida alguma, uma base tanto sob o ponto de vista teórico como empírico. Tem sido desde então uma questão permanente para a compreensão da família a coexistência de configurações de valores tradicionais e modernos, sobretudo, da família urbana, examinada como espaço das relações hierárquicas entre gêneros e entre gerações, por um lado, e por outro, espaço de socialização de indivíduos e da transmissão de valores igualitários. A insistência em trabalhar estas questões parece ser interessante para a compreensão das relações familiares em um momento do grupo doméstico em que esta mulher de 50 a 60 anos é tomada como referência para a pesquisa. Estou partindo de referências de alguns trabalhos sobre mulher, sobre trabalho da mulher, sobre envelhecimento, sobre as relações de gênero para realizar esta escolha geracional: as mulheres desta geração parecem viver uma experiência particular e distinta das gerações anteriores e da que as segue imediatamente e esta especificidade pode ser interessante para compreender as configurações das relações familiares contemporâneas.

As histórias de vida destas três gerações indicaram um novo percurso de pesquisa que me leva a aprofundar os sentidos e as práticas referidos ao legado de valores e dos bens materiais, à casa, à família, de jovens adultos e de suas figuras de referência como as mães, os pais, os avós, os amigos. Se no projeto de pesquisa anterior as mulheres de 50 a 60 anos foram o foco da discussão sobre mudança social e trajetória de vida, agora os jovens passam a ocupar este lugar. Mudanças no mundo do trabalho, reorganizações da vida doméstica, a reordenação e surgimento de novos temas sobre sexualidade, maternidade, parentalidade, os dramas individuais nos trânsitos entre mundos e entre opções de vida retomam e recriam as questões sobre trajetórias, memória e narrativas. 
Finalizo com Hannah Arendt:

A primeira coisa a ser observada é que não apenas o futuro - "a onda do futuro" -, mas também o passado, é visto como uma força, e não, como em praticamente todas as nossas metáforas, como um fardo com que o homem tem de arcar e de cujo peso morto os vivos podem ou mesmo devem se desfazer em sua marcha para o futuro.

Hannah Arendt (1979: 36-37)

\section{Referências}

AGUIAR, Odílio Alves. "Pensamento e narração em Hannah Arendt". In: MORAES, Eduardo Jardim e BIGNOTTO, Newton (orgs.). Hannah Arendt. Diálogos, reflexões e memórias. Belo Horizonte: Ed. UFMG, 2001. p.215-226.

ARENDT, Hannah. Entre o passado e o futuro. São Paulo: Editora Perspectiva, 1979.

HEILBORN, Maria Luiza e SORJ, Bila. "Estudos de gênero no Brasil". In: MICELLI, Sergio (org.). O que ler na ciência social brasileira (1970-1995). São Paulo: Editora Sumará: ANPOCS; Brasília: CAPES, 1999.

LINS DE BARROS, Myriam Moraes. "Testemunho de vida: um estudo antropológico de mulheres na velhice". In: Perspectivas Antropológicas da Mulher 2. Rio de Janeiro: Zahar Editores, 1981. p.11-70.

Autoridade e Afeto. Avós, filhos e netos na família brasileira. Rio de Janeiro: Jorge Zahar Editor, 1987.

"Memória de velhos e família" Revista Estudos

históricos, v.2, n.3. Rio de Janeiro: CPDOC/FGV, 1989. p. 29-42.

"O passado no presente: aos 70 falando do Rio de Janeiro”. In: Cadernos de Antropologia e Imagem, n. 4. Rio de Janeiro: UERJ/ Núcleo de Antropologia e Imagem, 1995. p. 91-106.

"Densidade da memória, Trajetória e Projeto de

Vida”. In: Estudos Feministas, v. 5, n.1. Florianópolis: UFSC, 1997. p. 140-147.

"A cidade dos velhos". In: VELHO, Gilberto (org.).

Antropologia Urbana. Cultura e sociedade no Brasil e em Portugal. Rio de Janeiro: Jorge Zahar Editor, 1999, p. 43-57.

. "Velhos e jovens no Rio de Janeiro". In: VELHO,

Gilberto e KUSCHNIR, Karina (org.) Pesquisas Urbanas. Desafios do trabalho antropológico. Rio de Janeiro: Jorge Zahar Ed, 2003. p. 156-173.

(org.). Velhice ou Terceira Idade? Estudos antropológicos sobre identidade, memória e política, $4^{\mathrm{a}}$. Ed.. Rio de Janeiro: Editora FGV, 2007.

"Três gerações femininas em famílias de camadas médias: trajetórias de vida e o projeto de autonomização". In: VELHO, G. \& DUARTE, L. F. D. (orgs.). Gerações, Família, Sexualidade. Rio de Janeiro: 7 Letras, 2009.

"Memória, experiência e narrativa". In: ROCHA, Ana

Luiza Carvalho da \& ECKERT, Cornelia. Individualismo, sociabilidade e memória. Anais do Colóquio. Porto Alegre: Editora Deriva, 2009 b.

LINS DE BARROS, Myriam Moraes e STROZENBERG, Ilana. Álbum de Família. Rio de Janeiro: Comunicação Contemporânea, 1993. 
MYERHOFF, Barbara. "Rites and Signs of ripening: the intertwining of Ritual". In: KERTZER, David I. \& KEITH, Jennie (ed.). Age \& Anthropological Theory. Ithaca: Cornell University Press, 1984.

SARLO, Beatriz. Tempo Passado. Cultura da memória e guinada subjetiva. São Paulo: Cia das Letras; Belo Horizonte: Ed. UFMG, 2007.

VELHO, Giberto. Individualismo e Cultura. Notas para uma Antropologia da Sociedade Contemporânea. Rio de Janeiro: Zahar Editores, 1981.

Recebido em: 19/12/2010

Aprovado em: 25/03/2011 